\title{
Hippocampus contributes to the maintenance but not the quality of visual information over time
}

\author{
David E. Warren, ${ }^{1}$ Melissa C. Duff, ${ }^{1,2}$ Neal J. Cohen, ${ }^{4,5,6}$ and Daniel Tranel ${ }^{1,3}$ \\ ${ }^{1}$ Department of Neurology, Carver College of Medicine, ${ }^{2}$ Department of Communications Sciences and Disorders, ${ }^{3}$ Department \\ of Psychology, University of lowa, lowa City, lowa 52242, USA; ${ }^{4}$ Department of Psychology, ${ }^{5}$ Beckman Institute, \\ ${ }^{6}$ Neuroscience Program, University of Illinois at Urbana-Champaign, Champaign Illinois 61801, USA
}

\begin{abstract}
The hippocampus has recently been implicated in the brief representation of visual information, but its specific role is not well understood. We investigated this role using a paradigm that distinguishes quantity and quality of visual memory as described in a previous study. We found that amnesic patients with bilateral hippocampal damage $(N=5)$ were less likely to remember test stimuli than comparison participants despite a brief maintenance interval $(900 \mathrm{msec})$. However, estimates of memory quality were similar for all groups. Our findings suggest that the hippocampus contributes to brief maintenance of visual information but does not contribute to the quality of that information.
\end{abstract}

[Supplemental material is available for this article.]

The ability to retain and integrate visual information across short intervals is critical to everyday life, demonstrated whenever one examines a painting, reads a manuscript, or remembers that a stoplight is still red. The psychological processes and neural mechanisms of these briefly held visual representations have been investigated (Jonides et al. 2008; Chun et al. 2011), but the specific contributions of many brain regions to the maintenance of visual information are unclear. For example, while the medial temporal lobe (MTL) and hippocampus are often associated with the formation of lasting declarative memories (Scoville and Milner 1957; Cohen and Squire 1980), MTL and hippocampus have also been implicated in the representation of visual information over very short intervals in animal models (Eacott et al. 1994; Murray and Bussey 1999; Bussey et al. 2002; Cowell et al. 2006) and more recently in humans (Olson et al. 2006; Barense et al. 2007; Lee et al. 2012; Warren et al. 2012). However, it is not clear whether the hippocampus and MTL contribute to the maintenance of visual representations, the quality of visual representations, or both.

Neuropsychological studies have shown that damage to MTL structures including the hippocampus causes impairment in performance on many tasks at short delays (Barense et al. 2005, 2007; Lee et al. 2005a,b; Hannula et al. 2006; Lee and Rudebeck 2010; Warren et al. 2010, 2011, 2012; Kurczek et al. 2013; Watson et al. 2013). Typically, these investigations have used binary yes/no or forced choice recognition tasks that cannot address how hippocampal damage might change the quality of mental representations. Tasks that permit graded responses have shown that MTL and hippocampal damage increase the variance of responses over time relative to neurologically normal participants (Sidman et al. 1968; Warren et al. 2010), but have not explained any underlying representational changes.

Zhang and Luck (2008) developed a theory and method sufficient to inform this issue by beginning with the premise that mental representations are inherently noisy. From this perspec-

\section{Corresponding author: david-e-warren@uiowa.edu}

Article is online at http://www.learnmem.org/cgi/doi/10.1101/lm.037127.114. tive, representational changes in short-delay tasks (whether in healthy participants or those with hippocampal damage) could be due to: added noise in mental representations that reduce their quality, leading to test-time mismatch with the original stimulus; increased probability that a stimulus is completely forgotten; or a combination of these phenomena (Fig. 1A). Studies of visual working memory in healthy participants suggest that visual representations follow the second course, disappearing from memory rather than decreasing in quality over time (Zhang and Luck 2009, but see Bays et al. 2009). Critically, the method of Zhang and Luck $(2008,2009,2011)$ supports independent estimation of the probability of a tested item being represented in memory and the quality of memory representations, providing significant advantages over binary response tasks.

Here, we evaluated the necessity of hippocampus for the brief maintenance of simple visual information using a neuropsychological approach. We tested neurological patients with amnesia $(N=5,1 \mathrm{~F} / 4 \mathrm{M})$; patients with brain damage excluding MTL and hippocampus ("BDC"; $N=14,6 \mathrm{~F} / 8 \mathrm{M}, 1 \mathrm{M}$ later excluded for color blindness); and healthy comparison participants ("NC"; $N=$ $19,9 \mathrm{~F} / 10 \mathrm{M}$ ) of similar age and educational attainment (Table 1 ; $P>0.05)$ using a task that provides insight into the quantity and quality of visual memory representations at short delays (Fig. 1B; Zhang and Luck 2008). Participants saw 1, 3, or 6 color stimuli presented briefly (100 msec) and $900 \mathrm{msec}$ later responded to a memory probe in a particular location by selecting the color previously occupying that location from a color ring. Based on prior research (Sidman et al. 1968; Downes et al. 1998; Warren et al. 2010), we hypothesized that amnesic patients would show a broader distribution of responses than comparisons, reflecting reduced retention of visual information versus comparisons.

\footnotetext{
C 2014 Warren et al. This article is distributed exclusively by Cold Spring Harbor Laboratory Press for the first 12 months after the full-issue publication date (see http://learnmem.cshlp.org/site/misc/terms.xhtml). After 12 months, it is available under a Creative Commons License (AttributionNonCommercial 4.0 International), as described at http://creativecommons. org/licenses/by-nc/4.0/.
} 
A

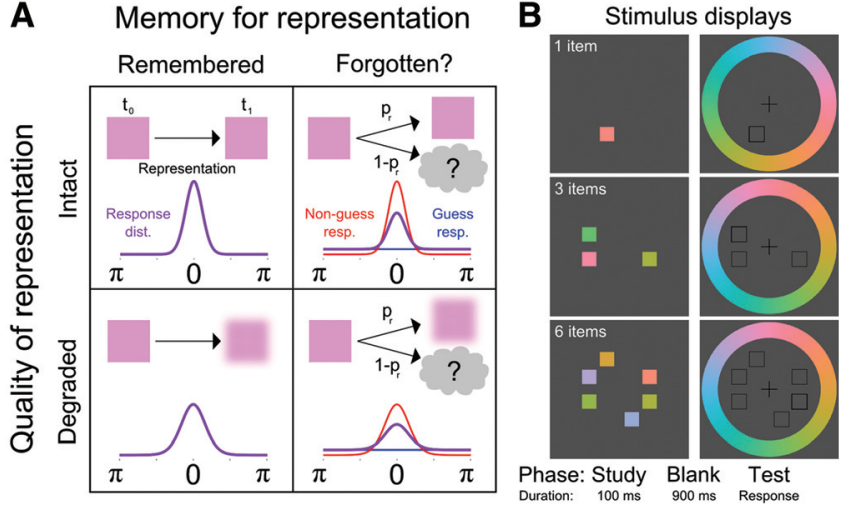

Figure 1. Model assumptions and trial sequence. $(A)$ Based on the model of Zhang and Luck (2008), we hypothesized that briefly maintained visual representations could change in two dissociable ways. Representations could be remembered or forgotten (left and right columns), and the quality of representations could remain intact or be reduced (top and bottom rows). Each panel diagrams a combination of forgetting and degradation of the visual representation (top), and the associated distribution of responses (bottom) around the target value $(0$, with maximum response error of $\pi$ ). Expected response distributions (purple) could change in two ways depending on changes to underlying representations: reduced quality would yield a broader distribution of responses; while forgetting some representations entirely would yield a hybrid of a uniform distribution reflecting guesses (blue) and a targetcentered distribution of memory-guided responses (red). We predicted that hippocampal damage would reduce probability of memory for studied items but not degrade representations (upper right). (B) In each trial, participants saw 1, 3, or 6 color squares for 100 msec (white text was not presented). After a $900-\mathrm{msec}$ blank interval, the target location was indicated with a thick open square. Participants selected the color that was seen in that location from the color wheel.

Importantly, the sensitive nature of our task and analysis also allowed us to form novel hypotheses regarding the specific nature of the impairment. Following the well-established role of the MTL and hippocampus in memory, we predicted that the visual representations of amnesic patients would be more susceptible to forgetting, but that representations which were available at test would be distributed similarly to those of comparisons.

Task materials were based on those described by Zhang and Luck (2008). Displays consisted of closed squares of specific colors that subtended $2^{\circ}$ of visual angle (horizontally and vertically), open black squares subtending $2.04^{\circ}$ and $2.2^{\circ}$ of visual angle, and a colored ring with an inner radius of $7.1^{\circ}$ of visual angle and an outer radius of $9.3^{\circ}$ of visual angle (Fig. 1B). For the colored ring, 180 equal-luminance colors were selected from CIE $L^{*} a^{*} b^{*}$ color space by sampling the space around $L=70, a=0$, $b=13$ in 180 even steps around the circumference of a circle in the $a^{*} b^{*}$ plane with radius 45 . All values were converted to RGB and checked for compatibility with that color space. Colors for the closed square stimuli were drawn from this 180-color spectrum. Visual stimuli were presented at a distance of $50 \mathrm{~cm}$ on a 21-in LCD monitor with a vertical refresh rate of $60 \mathrm{~Hz}$ (MultiSync 2190UXi, NEC Corporation of America). Responses were made with a computer mouse.

Our procedure adapted the Zhang and Luck paradigm (2008). Participants were seated in front of a computer display. At the beginning of each block, written instructions were presented on the screen: "Colored squares will briefly appear near the center of the screen. Remember all of the colors. When one position is cued, indicate the color from that position." Complementary verbal instructions by the experimenter emphasized key task components, and participant comprehension was evaluated. A prac- tice block (15 three-item trials) preceded the main test phase. The main test phase consisted of three blocks containing 150 trials including 50 trials each for 1,3 , and 6 items in a unique random order.

Participants initiated each trial with a mouse click; a central fixation cross changed color, and $\sim 1$ sec later the trial began (the stimulus onset asynchrony jittered by $\pm 125 \mathrm{msec}$ ). The trial sequence (Fig. 1B) was: a study display containing one or more color squares (100 msec); a blank display (900 msec); and the test display (presented until response) which included a mouse cursor, open squares surrounding each position that previously held a colored square, a cue in the form of open square with a thicker outline surrounding the test location, and the color ring. Participants indicated which color had been presented in the cued location by clicking that color on the color ring, and guessed if unsure.

Based on the distribution of test-time responses, three parameters were estimated for each participant: $p_{r}$, the probability that the probe item was in memory at test (i.e., the "quantity" of information in memory); $k$, the concentration of the response distribution around $\mu$ (i.e., the "quality" of information in memory); and $\mu$, the mean of the response distribution. Parameter estimation was based on previously reported methods (Zhang and Luck 2008), and is described in the Supplemental Material. All trials with response times $\leq 15 \mathrm{sec}$ were used in the parameter estimation procedure. Group differences were evaluated for the three parameters $\left(p_{r}, \kappa, \mu\right)$. No significant differences were found for $\mu$ (see Supplemental Material). In order to address the possibility that nontarget items significantly influenced response distributions, we also estimated parameters for an alternative model (Bays et al. 2009). Results were generally consistent with the main findings; the alternative approach and results are described in the Supplemental Material. Between-group differences for all dependent variables were tested using repeated-measures ANOVA implemented as a hierarchical linear model with participants as a random effect, group as a between-participants fixed effect, and number of items as a within-participants fixed effect. Planned between-group and between-condition comparisons were conducted using nonpaired, equal-variance $t$-tests. Permutation tests of the planned comparisons are reported as $p_{\text {perm }}$ and were calculated as follows: bootstrapped distributions were created by assigning group membership to the data in $10^{5}$ randomly selected permutations, recording the statistic value for each permutation, and determining the percentile rank of the observed statistic value in the bootstrapped distribution. Effect size was measured with an unbiased variant of Cohen's $d$ that accounts for small sample sizes $\left(d_{\mathrm{unb}}\right)$ (Grissom and Kim 2012, p. 70). Response time was not a dependent variable of interest, but a similar, exploratory analysis is presented in the Supplemental Material and Table S2.

The probability of an item being present in memory at test $\left(p_{r}\right)$ differed between groups and was significantly reduced in amnesic patients (Fig. 2A; Supplemental Table S1). Between-group differences in $p_{r}$ were significant $\left[F_{(2,34)}=4.597, P<0.001\right]$, and planned comparisons between groups for each number of items showed that amnesic patients were significantly impaired relative to the $\mathrm{NC}$ and $\mathrm{BDC}$ groups in the three-item condition $\left[\mathrm{NC}, T_{(22)}=2.879, P=0.009, p_{\text {perm }}=0.006 ; \mathrm{BDC}, T_{(16)}=3.020\right.$, $\left.P=0.008, p_{\text {perm }}=0.005\right]$, at least marginally impaired in the six-item condition $\left[\mathrm{NC}, T_{(22)}=2.070, P=0.050, p_{\text {perm }}=0.015\right.$; BDC, $\left.T_{(16)}=2.152, P=0.047, p_{\text {perm }}=0.029\right]$, but no more than marginally impaired in the one-item condition $\left[\mathrm{NC}, T_{(18)}=\right.$ $1.878, P=0.077, p_{\text {perm }}=0.073 ; \mathrm{BDC}, T_{(16)}=1.611, P=0.127$, $p_{\text {perm }}=0.133$ ]. The lack of a significant difference for one item may have reflected a ceiling effect as all groups had values of $p_{r}$ near 1 (see Supplemental Table S1 and Discussion). The NC and BDC groups did not differ in any condition [one item, 
Table 1. Demographic and neuropsychological data characterizing participants

\begin{tabular}{|c|c|c|c|c|c|c|c|c|c|c|c|c|c|c|c|}
\hline ID & Age & Sex & Edu. & Eti. & Chr. & Hand & FSIQ & VIQ & PIQ & DS & GMI & AVLT & CFT C/R & BVRT & $\mathrm{HcV}$ \\
\hline 1846 & 49 & $\mathrm{~F}$ & 14 & An./SE & 19 & 100 & 84 & 89 & 79 & 10 & 57 & $7 / 3$ & $28 / 6$ & 5 & $-4.23^{*}$ \\
\hline 1951 & 60 & M & 16 & HSE & 32 & 100 & 106 & 105 & 106 & 9 & 57 & $9 / 1$ & $32 / 4$ & 6 & $\gg$ \\
\hline 2308 & 56 & $M$ & 16 & HSE & 13 & -100 & 98 & 95 & 92 & 9 & 45 & $5 / 0$ & $32 / 0$ & 6 & $\gg$ \\
\hline 2363 & 56 & M & 18 & An. & 14 & 100 & 98 & 112 & 83 & 8 & 73 & $8 / 0$ & $26 / 5$ & 6 & $-2.64^{*}$ \\
\hline 2563 & 58 & M & 16 & An. & 13 & -80 & 94 & 91 & 98 & 14 & 63 & $10 / 4$ & $36 / 7$ & 7 & NA \\
\hline $\operatorname{Amn}(N=5)$ & $\begin{array}{l}55.8 \\
(4.1)\end{array}$ & $4 \mathrm{M} 1 \mathrm{~F}$ & $\begin{array}{l}16.0 \\
(1.4)\end{array}$ & - & $\begin{array}{l}18.2 \\
(8.1)\end{array}$ & - & $\begin{array}{l}96.0 \\
(8.0)\end{array}$ & $\begin{array}{l}98.4 \\
(9.8)\end{array}$ & $\begin{array}{c}91.6 \\
(11.0)\end{array}$ & $\begin{array}{l}10.0 \\
(2.3)\end{array}$ & $\begin{array}{c}59.0 \\
(10.2)\end{array}$ & $\begin{array}{c}7.8 / 1.6 \\
(1.9 / 1.8)\end{array}$ & $\begin{array}{l}30.8 / 3.9 \\
(4.4 / 2.7)\end{array}$ & $\begin{array}{c}6.0 \\
(0.7)\end{array}$ & - \\
\hline $\mathbf{B D C}(N=13)$ & $\begin{array}{l}61.5 \\
(8.9)\end{array}$ & $7 \mathrm{M} 6 \mathrm{~F}$ & $\begin{array}{l}14.1 \\
(2.0)\end{array}$ & - & $\begin{array}{l}11.1 \\
(8.3)\end{array}$ & - & $\begin{array}{l}110.7 \\
(9.8)\end{array}$ & $\begin{array}{l}108.8 \\
(11.2)\end{array}$ & $\begin{array}{l}110.5 \\
(11.1)\end{array}$ & $\begin{array}{l}10.5 \\
(2.5)\end{array}$ & - & $\begin{array}{c}12.8 / 10.2 \\
(2.3 / 3.2)\end{array}$ & $\begin{array}{c}31.6 / 18.0 \\
(3.1 / 7.0)\end{array}$ & $\begin{array}{c}7.9 \\
(2.7)\end{array}$ & - \\
\hline NC $(N=19)$ & $\begin{array}{l}53.1 \\
(6.7)\end{array}$ & $10 \mathrm{M} 9 \mathrm{~F}$ & $\begin{array}{l}15.7 \\
(1.9)\end{array}$ & - & - & - & - & - & - & - & - & - & - & - & - \\
\hline
\end{tabular}

Individual scores are presented for each participating amnesic patient, followed by amnesic (Amn) group means, brain-damaged comparison (BDC) group means, and healthy normal comparison (NC) group means (standard deviations in parentheses). The significant memory impairment of the amnesic group is evident in several neuropsychological measures. Note that these scores may reflect updated test results based on periodic case reviews, and are contemporaneous with this study. See Lezak et al. (2012) for further information about individual measures. Abbreviations: Age, years; Edu., education, years; Chr., chronicity, years since injury; Hand, handedness (+100 = fully right handed, $-100=$ fully left handed); Eti., etiology; Anoxia/An., anoxic/ischemic episode, SE, status epilepticus, HSE, herpes simplex encephalitis; FSIQ, WAIS-III full-scale IQ (WAIS-IV was used for some BDC patients); VIQ, verbal IQ; PIQ, performance IQ; DS, WAIS 3/4 Digit Span; WMS-III GMI, general memory index; AVLT, Rey Auditory Verbal Learning Task, trial 5/30-min delay; CFT, complex figure task copy/recall; BVRT, Benton visual retention test number correct; $\mathrm{HcV}$, bilateral hippocampal volumes per Allen et al. (2006). Volumes are expressed in Studentized residuals relative to normative expectations: ${ }^{*}$, reported by Allen et al. (2006); $\gg$, residual value not available, but near-complete bilateral hippocampal lesion in the context of larger brain lesions (see Feinstein et al. 2010; Cavaco et al. 2012); NA, volumetric measurements unavailable due to contraindications for MRI (e.g., pacemaker).

$T_{(26)}=0.445, P=0.660, p_{\text {perm }}=0.328$; three items, $T_{(30)}=1.047$, $P=0.304, \quad p_{\text {perm }}=0.150 ;$ six items, $T_{(30)}=1.089, P=0.285$, $\left.p_{\text {perm }}=0.143\right]$.

In addition to between-group effects, $p_{r}$ was affected by the number of items presented $\left[F_{(2,64)}=363.874, P<0.001\right]$, but the interaction of the group and number-of-items factors was not significant $\left[F_{(4,64)}=1.428, P=0.235\right]$. For all groups the pattern was similar (Fig. 2A): $p_{r}$ was greatest for one item; relatively less for three items; and least for six items. Planned within-group comparisons between $p_{r}$ for presentations of one versus three items and three versus six items showed that this pattern was significant for all groups [one item versus three items, each $T>4.5$, each $P<0.0025$, each $p_{\text {perm }}<0.005$, each $d_{\text {unb }}>1.9$; three items versus six items, each $T>4.0$, each $P<0.005$, each $p_{\text {perm }}<0.001$, each $\left.d_{\text {unb }}>2.4\right]$. Thus, when more stimuli were presented, the probability of any given stimulus being present in memory at test was reduced.

The quality of memory representations (к) was influenced by the number of items in a display, but did not differ between groups (Fig. 2B; Supplemental Table S1). The NC, BDC, and amnesic groups all had similar $\kappa\left[F_{(2,34)}=0.229, P=0.796\right]$, and planned comparisons between groups for each number of items found no significant differences [each $T<1.4$, each $P>$ 0.19 , each $p_{\text {perm }}>0.09$ ]. Meanwhile, the number of items presented had a significant effect on $\kappa\left[F_{(2,64)}=17.478, P<0.001\right]$. Planned comparisons revealed the same pattern for each group: displays of one item produced the greatest value of $\kappa$ [one versus three items, each $T>3.2$, each $P<0.025$, each $p_{\text {perm }}<0.005$ ]; while presentations of three and six items produced values of $\kappa$ that were lower and not statistically different from each other [three versus six items, each $T<1.7$, each $P>0.10$, each $p_{\text {perm }}>$ 0.501]. There was no significant interaction of the group by condition $\left[F_{(4,64)}=0.427, P>0.789\right]$. This pattern of higher quality representations for one item than for either of the larger sets of items may reflect previously reported characteristics of visual working memory (Zhang and Luck 2008).

The observed deficit in brief maintenance of visual information by amnesic patients with hippocampal damage could be attributed to reduced memory capacity, reduced ability to maintain information over time, a combination of these factors, or still further causes. Our findings are compatible with a previously hy- pothesized role for the hippocampus in the on-line processing of visual information (Gallegos et al. 2006; Barense et al. 2007; Warren et al. 2011, 2012), and congruent with suggestions that short-term and long-term memory systems may not be neurally dissociable (Ranganath and Blumenfeld 2005). Moreover, we suggest that the role of the hippocampus in visual representation is inherently mnemonic and relational. For example, relational memory theory (Cohen and Eichenbaum 1993; Eichenbaum and Cohen 2001, Moses and Ryan 2006, Ranganath 2010; Eichenbaum and Cohen 2014) predicts that the hippocampus is necessary for the binding of arbitrarily related information (e.g., color and spatial location) irrespective of timescale. What our current methodology identifies as outright loss of information may include some responses in the three- and six-item conditions that
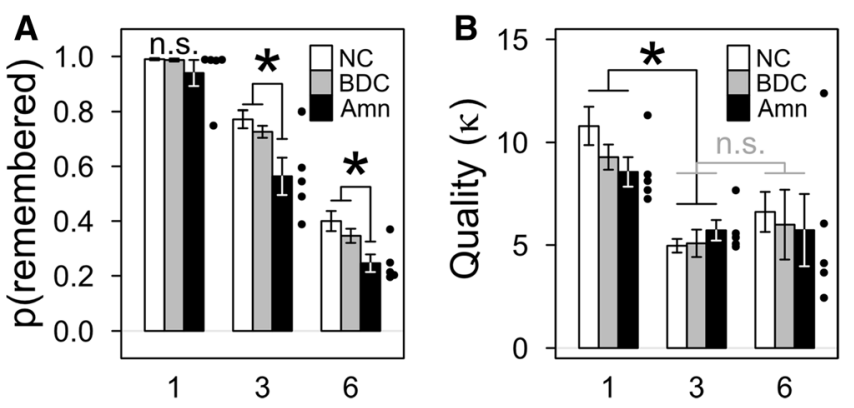

Figure 2. Damage to the hippocampus and MTL reduced the probability that an item would be remembered without altering the quality of memory representations. (A) Group means for the probability of remembering the tested item. Amnesic patients (Amn) were significantly $\left(^{*}\right)$ less likely to remember items at test overall and specifically for the three- and six-item conditions versus both comparison groups. Error bars show SEM, and the performance of individual amnesic patients is indicated by points. In the three- and six-item conditions patient 1846 performed better than the other amnesic patients and near the comparison means; more information and detailed parameter fits are provided in Supplemental Table S3. (B) Group means for the quality of remembered representations (i.e., discounting forgetting) were similar for all item conditions, but quality was significantly $\left(^{*}\right)$ greater in the one-item condition than the three- and six-item conditions. Error bars and points as in panel $A$. 
involve color-location association errors on the part of participants, and relational memory theory predicts that hippocampal damage would increase these errors (Watson et al. 2013). In this context, the relatively preserved performance of amnesic patients in the one-item condition could be due to a lack of relational demands. However, a supplemental analysis using the model of Bays et al. (2009), which attempts to account for responses driven by nontarget items, did not provide strong evidence for increased color-location association errors by amnesic patients (see Supplemental Results).

We suggest that the observed impairment in the brief maintenance of visual information by amnesic patients is due to impairments in on-line processing of relations due to hippocampal damage, but other data and interpretations are relevant. Zhang and Yonelinas (2012) tested a mixed group of unilateral temporal lobectomy and anoxic amnesic patients using similar methodology, and reported a change in the quality of memory representations (i.e., decreased $\kappa$ ) rather than the probability of memory (decreased $p_{r}$ ). Both studies clearly show that hippocampal damage can impair performance on the Zhang and Luck (2008) task; different patterns of results could be attributable to patient anatomy or details of task implementations. Meanwhile, Jeneson et al. $(2010,2012)$ and Jeneson and Squire (2011) have suggested that deficits at similar timescales are attributable to the inability of amnesic patients to remember information exceeding the capacity of short-term memory because they lack normal declarative memory systems. We note that our task used a brief maintenance interval (900 msec) and that the amnesic group showed an impairment that was significant for dislays containing as few as three items. Jeneson et al. (2012) have previously described displays with these characteristics as within the capacity of short-term memory, and we concur with that description. We attribute our finding of impairment in this context to the sensitive nature of our experimental methodology.

Despite our robust findings, the study had some limitations. As in most neuropsychological investigations studying severely amnesic patients, our sample size was relatively small. However, the study had enough power to uncover significant differences, and our main findings had substantial effect sizes. Interestingly, while we observed impairment for the amnesic group that was greatest for presentations of three and six items, presentations of one item did not reliably produce impairment. Single items may have been maintained normally by the amnesic group, but it is possible that differences in the maintenance of a single item were obscured by a ceiling effect (especially among comparison participants). Further exploration of the parameter space in this task could attempt to address ceiling effects by including a two-item condition or a reducing item exposure time.

In summary, we found that hippocampal damage was related to reduced probability of remembering briefly maintained mental representations of visual information, indicating that the hippocampus normally makes important contributions to remembering visual information over very short intervals. Our results suggest that future investigations of visual representations in hippocampal amnesic patients could benefit from using graded rather than binary response designs in order to collect rich response distributions. We predict that populations with damage or dysfunction of hippocampus will show deficits at short delays when tested with stimuli of visual or other modalities, further demonstrating the contributions of hippocampus to brief representation and on-line processing.

\section{Acknowledgments}

We thank the following funding agencies: NINDS P01 NS19632 (DT); NIDCD R01 DC011755 (M.C.D.); NIMH R01 MH062500
(N.J.C. and D.E.W.). We thank the participating patients and their families for facilitating this investigation. We thank Samuel H. Jones and Kendra Schmitt for their assistance with this project. Competing interest statement: The authors report no perceived or actual conflicts of interest.

\section{References}

Allen JS, Tranel D, Bruss J, Damasio H. 2006. Correlations between regional brain volumes and memory performance in anoxia. J Clin Exp Neuropsychol 28: 457-476.

Barense MD, Bussey TJ, Lee ACH, Rogers TT, Davies RR, Saksida LM, Murray EA, Graham KS. 2005. Functional specialization in the human medial temporal lobe. J Neurosci 25: 10239-10246.

Barense MD, Gaffan D, Graham KS. 2007. The human medial temporal lobe processes online representations of complex objects. Neuropsychologia 45: 2963-2974.

Bays PM, Catalao RF, Husain M. 2009. The precision of visual working memory is set by allocation of a shared resource. J Vis 9: 7.1-7.11.

Bussey TJ, Saksida LM, Murray EA. 2002. Perirhinal cortex resolves feature ambiguity in complex visual discriminations. Eur J Neurosci 15: $365-374$.

Cavaco S, Feinstein JS, van Twillert H, Tranel D. 2012. Musical memory in a patient with severe anterograde amnesia. J Clin Exp Neuropsychol 34: 1089-1100.

Chun MM, Golomb J, Turk-Browne NB. 2011. A taxonomy of external and internal attention. Annu Rev Psychol 62: 73-101.

Cohen NJ, Eichenbaum H, ed. 1993. Memory, amnesia, and the hippocampal system. The MIT Press, Cambridge, MA.

Cohen NJ, Squire LR. 1980. Preserved learning and retention of patternanalyzing skill in amnesia: dissociation of knowing how and knowing that. Science 210: 207-210.

Cowell RA, Bussey TJ, Saksida LM. 2006. Why does brain damage impair memory? A connectionist model of object recognition memory in perirhinal cortex. J Neurosci 26: 12186-12197.

Downes JJ, Holdstock JS, Symons V, Mayes AR. 1998. Do amnesics forget colours pathologically fast? Cortex 34: 337-355.

Eacott MJ, Gaffan D, Murray EA. 1994. Preserved recognition memory for small sets, and impaired stimulus identification for large sets, following rhinal cortex ablations in monkeys. Eur J Neurosci 6: $1466-1478$

Eichenbaum H, Cohen NJ. 2001. The hippocampal memory system. In From conditioning to conscious recollection: memory systems of the brain (Eichenbaum H, Cohen NJ), pp. 305-343. Oxford University Press, New York, NY.

Eichenbaum H, Cohen NJ. 2014. Can we reconcile the declarative memory and spatial navigation views on hippocampal function? Neuron $\mathbf{8 3}$ : 764-770.

Feinstein JS, Rudrauf D, Khalsa SS, Cassell MD, Bruss J, Grabowski TJ, Tranel D. 2010. Bilateral limbic system destruction in man. J Clin Exp Neuropsychol 32: 88-106.

Gallegos D, Tranel D, Luck SJ. 2006. Visual working memory in patients with bilateral hippocampal damage. 13th Annual Meeting of the Cognitive Neuroscience Society, p. 237.

Grissom RJ, Kim JJ ed. 2012. Effect sizes for research: univariate and multivariate applications. Routledge, New York, NY.

Hannula DE, Tranel D, Cohen NJ. 2006. The long and the short of it: relational memory impairments in amnesia, even at short lags. J Neurosci 26: 8352-8359.

Jeneson A, Squire LR. 2011. Working memory, long-term memory, and medial temporal lobe function. Learn Mem 19: 15-25.

Jeneson A, Mauldin KN, Squire LR. 2010. Intact working memory for relational information after medial temporal lobe damage. J Neurosci 30: $13624-13629$.

Jeneson A, Wixted JT, Hopkins RO, Squire LR. 2012. Visual working memory capacity and the medial temporal lobe. J Neurosci 32: $3584-3589$.

Jonides J, Lewis RL, Nee DE, Lustig CA, Berman MG, Moore KS. 2008. The mind and brain of short-term memory. Annu Rev Psychol 59: 193-224.

Kurczek J, Brown-Schmidt S, Duff M. 2013. Hippocampal contributions to language: evidence of referential processing deficits in amnesia. J Exp Psychol Gen 142: 1346-1354.

Lee ACH, Rudebeck SR. 2010. Human medial temporal lobe damage can disrupt the perception of single objects. J Neurosci 30: 6588-6594.

Lee ACH, Buckley MJ, Pegman SJ, Spiers H, Scahill VL, Gaffan D, Bussey TJ, Davies RR, Kapur N, Hodges JR, et al. 2005a. Specialization in the medial temporal lobe for processing of objects and scenes. Hippocampus 15: 782-797.

Lee ACH, Bussey TJ, Murray EA, Saksida LM, Epstein RA, Kapur N, Hodges JR, Graham KS. 2005b. Perceptual deficits in amnesia: 
challenging the medial temporal lobe 'mnemonic' view. Neuropsychologia 43: 1-11.

Lee ACH, Yeung LK, Barense MD. 2012. The hippocampus and visual perception. Front Hum Neurosci 6: 91.

Lezak MD, Howieson DB, Bigler ED, Tranel D, ed. 2012. Neuropsychological assessment. Oxford University Press, New York.

Moses SN, Ryan JD. 2006. A comparison and evaluation of the predictions of relational and conjunctive accounts of hippocampal function. Hippocampus 16: 43-65.

Murray EA, Bussey TJ. 1999. Perceptual-mnemonic functions of the perirhinal cortex. Trends Cogn Sci 3: 142-151.

Olson IR, Moore KS, Stark M, Chatterjee A. 2006. Visual working memory is impaired when the medial temporal lobe is damaged. J Cogn Neurosci 18: $1087-1097$.

Ranganath C. 2010. A unified framework for the functional organization of the medial temporal lobes and the phenomenology of episodic memory. Hippocampus 20: 1263-1290.

Ranganath C, Blumenfeld RS. 2005. Doubts about double dissociations between short- and long-term memory. Trends Cogn Sci 9: 374-380.

Scoville WB, Milner B. 1957. Loss of recent memory after bilateral hippocampal lesions. J Neurol Neurosurg Psychiatry 20: $11-21$

Sidman M, Stoddard LT, Mohr JP. 1968. Some additional quantitative observations of immediate memory in a patient with bilateral hippocampal lesions. Neuropsychologia 6: 245-254.
Warren DE, Duff MC, Tranel D, Cohen NJ. 2010. Medial temporal lobe damage impairs representation of simple stimuli. Front Hum Neurosci 4: 35 .

Warren DE, Duff MC, Tranel D, Cohen NJ. 2011. Observing degradation of visual representations over short intervals when medial temporal lobe is damaged. J Cogn Neurosci 23: 3862-3873.

Warren DE, Duff MC, Jensen U, Tranel D, Cohen NJ. 2012. Hiding in plain view: lesions of the medial temporal lobe impair online representation. Hippocampus 22: 1577-1588.

Watson PD, Voss JL, Warren DE, Tranel D, Cohen NJ. 2013. Spatial reconstruction by patients with hippocampal damage is dominated by relational memory errors. Hippocampus 23: 570-580.

Zhang W, Luck SJ. 2008. Discrete fixed-resolution representations in visual working memory. Nature 453: 233-235.

Zhang W, Luck SJ. 2009. Sudden death and gradual decay in visual working memory. Psychol Sci 20: 423-428.

Zhang W, Luck SJ. 2011. The number and quality of representations in working memory. Psychol Sci 22: 1434-1441.

Zhang W, Yonelinas AP. 2012. The influence of medial temporal lobe damage on capacity and precision in visual working memory. In Paper presented at the Annual Meeting of the the Cognitive Neuroscience Society, Chicago, IL.

Received September 26, 2014; accepted in revised form October 14, 2014. 


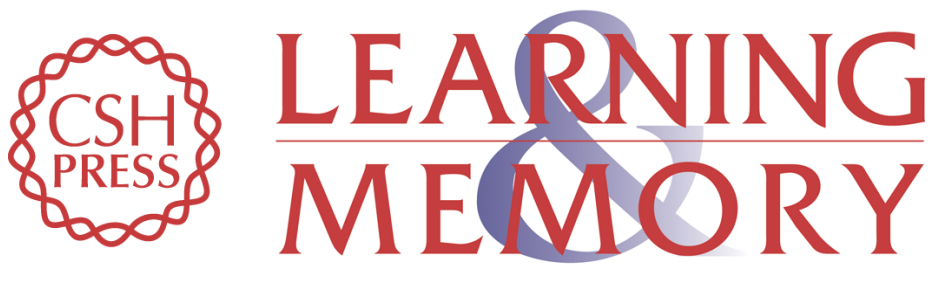

\section{Hippocampus contributes to the maintenance but not the quality of visual information over time}

David E. Warren, Melissa C. Duff, Neal J. Cohen, et al.

Learn. Mem. 2015, 22:

Access the most recent version at doi:10.1101/Im.037127.114

\section{Supplemental http://learnmem.cshlp.org/content/suppl/2014/12/05/22.1.6.DC1 Material}

References This article cites 37 articles, 9 of which can be accessed free at: http://learnmem.cshlp.org/content/22/1/6.full.html\#ref-list-1

Creative This article is distributed exclusively by Cold Spring Harbor Laboratory Press for the Commons first 12 months after the full-issue publication date (see

License http://learnmem.cshlp.org/site/misc/terms.xhtml). After 12 months, it is available under a Creative Commons License (Attribution-NonCommercial 4.0 International), as described at http://creativecommons.org/licenses/by-nc/4.0/.

Email Alerting Receive free email alerts when new articles cite this article - sign up in the box at the Service top right corner of the article or click here. 